University of Rhode Island

DigitalCommons@URI

\title{
Considering Future Sea Level Change in Maritime Infrastructure Design: A Survey of US Engineers
}

\author{
Benjamin Sweeney \\ University of Rhode Island \\ Austin Becker \\ University of Rhode Island, abecker@uri.edu
}

Follow this and additional works at: https://digitalcommons.uri.edu/maf_facpubs

\section{The University of Rhode Island Faculty have made this article openly available.}

Please let us know how Open Access to this research benefits you.

This is a pre-publication author manuscript of the final, published article.

Terms of Use

This article is made available under the terms and conditions applicable towards Open Access

Policy Articles, as set forth in our Terms of Use.

\section{Citation/Publisher Attribution}

Sweeney, B. and Becker, A., 2020. Considering Future Sea Level Change in Maritime Infrastructure Design: A Survey of US Engineers. Journal of Waterway, Port, Coastal, and Ocean Engineering, 146(4), p.04020019. https://doi.org/10.1061/(ASCE)WW.1943-5460.0000583 Available at: https://doi.org/10.1061/(ASCE)WW.1943-5460.0000583 


\title{
Considering Future Sea Level Change in Maritime Infrastructure Design: A Survey of U.S. Engineers
}

\author{
Benjamin Sweeney ${ }^{1}$ and Austin Becker ${ }^{2}$
}

1. Department of Marine Affairs, University of Rhode Island, 1 Greenhouse Road, Kingston, RI 02881, benjaminsweeney@uri.edu

2. Department of Marine Affairs, University of Rhode Island, 1 Greenhouse Road, Kingston, RI 02881, abecker@uri.edu

Please cite as:

Sweeney, B. and Becker, A., 2020. Considering Future Sea Level Change in Maritime Infrastructure Design: A Survey of US Engineers. Journal of Waterway, Port, Coastal, and Ocean Engineering, 146(4), p.04020019. https://doi.org/10.1061/(ASCE)WW.1943$\underline{5460.0000583}$

\section{$\underline{\text { Abstract }}$}

Seaports are particularly vulnerable to coastal hazards such as hurricanes and flooding due to their location. Sea level change (SLC) can magnify the impacts of those coastal hazards, threatening the resilience of ports. Engineers must design port infrastructure that is adequately prepared for the amount of SLC expected within the design life of the structure. However, uncertainty of SLC projections coupled with the long service lives of port infrastructure present unique challenges to do so. Through an online survey of 85 U.S. port and maritime infrastructure engineers, this research reflects the U.S. engineering community's attitude and approach to planning for SLC for maritime infrastructure projects. Only $29 \%$ of 
respondents indicated their organization had an internal SLC policy, design, or planning document.

Furthermore, results show the lack of regulatory design standards in this area leads to engineers and their clients disregarding SLC more frequently. There is a clear need for collaboration among stakeholders to develop practical design methods for designing resilient port infrastructure.

\section{Introduction}

Sea level rise increases risks to wharves, docks, piers, and other maritime infrastructure (Asariotis and Benamara 2012). As sea level rises (NRC 2012; Parris et al. 2012; IPCC 2013), port engineers will need to design more resilient structures that considers SLC projections (Esteban et al. 2013; Becker et al. 2015). Resilient ports and maritime structures are those that are able to "bounce back" after hurricanes, coastal storms, flooding, and other coastal hazards. SLC has a measureable effect on the severity of these coastal hazards, and requires engineers to anticipate and proactively prepare for it. The uncertainty of SLC projections, along with a variety of guidelines and recommendations for managing SLC, presents a new challenge for engineers (Becker et al. 2015). But, incorporating SLC projections into port structure design is critical due to the long working life of such structures, which sometimes can exceed 100 years. There are strong economic and social incentives for seaports to provide long-term resilience against coastal hazards. Billions of dollars in damages and service disruptions (Haveman and Shatz 2006) affect the livelihoods of those who depend on the port (Becker et al. 2013). Currently, the U.S. has no standard nationwide guidance for how to incorporate SLC projections into design (Toilliez 2018). This leaves engineers to make subjective decisions based on inconsistent guidance and information.

To better understand how different firms, organizations, and individual engineers incorporate SLC into the design of port infrastructure, and to identify industry needs to improve the resilience of ports, the researchers conducted an online survey of U.S. port and maritime infrastructure engineers to address the following questions:

1. In what capacity are port infrastructure designers incorporating a sea level change projection into their design specifications for large-scale port engineering projects? 
2. Where do incentives and disincentives originate for U.S. engineering firms to incorporate sea level change into the design specifications of large-scale port engineering projects?

3. For engineering firms that are incorporating sea level change, what strategies are the port infrastructure designers in those firms implementing in the design specifications of largescale port engineering projects to cope with the scientific uncertainty of sea level change?

Previous research suggests the importance (Becker et al. 2013; Becker et al. 2015) and the difficulty (Milly et al. 2008; Ahern 2011; Olsen 2015) of designing more resilient infrastructure, but there is little understanding of the current state of the practice. Surveys have targeted port directors and other port operations personnel to gauge climate change planning efforts more generally (Bierling and Lorented 2008; Becker et al. 2012), but while port directors play a role in planning for SLC, port engineers often make final determinations about how to incorporate SLC into infrastructure design. Thus, the survey described in this paper focuses on engineers and their decision making processes to assess how SLC is currently considered in the design of port and maritime infrastructure. The findings discussed throughout this paper build upon preliminary work focused on identifying incentives and barriers to designing port infrastructure for SLC (Sweeney, 2019). By conducting a first-of-its-kind assessment of the current level at which engineers consider SLC in the design of port and maritime infrastructure, the industry can better evaluate the link between SLC research and engineering implementation, and determine strategies to increase the effectiveness of that link. Additionally, this research points to areas where intervention can occur to effectively promote better resilience design methods. The baseline data resulting from this research can also be used for tracking how engineers change their approach to incorporating SLC into design over time, as SLC research advances and design standards change. 


\section{Background}

\section{$\underline{\text { SLC threatens U.S. maritime infrastructure }}$}

Temperature records from 1850-2016 provide evidence of a long-term global warming trend (WMO 2018). Near-surface ocean temperature and salinity data suggest increasing ocean heat content (Dieng et al. 2017), which in turn raises average global sea level due to thermal expansion coupled with melting ice sheets (Dieng 2017). Global mean sea level rise projections (GMSLR) range from 0.3 to 2.5 meters by 2100 (IPCC 2013; Jevrejeva et al. 2016; Sweet et al. 2017), but regional and local scale SLC is less understood (Bilbao et al. 2015). SLC projections vary across coastal regions of the U.S., with parts of Alaska projected to experience a sea level decrease due to land uplift, while the Louisiana coast may have a higher relative rise due to land subsidence.

The rate of SLC depends on which greenhouse gas emission pathway the world tracks along (Church et al. 2013) and is also subject to the variability in glacial melting, changes in land water storage, and coastal erosion (Rahmstorf 2007; DeConto and Pollard 2016). While SLC uncertainty over the next few decades (2030-2060) is relatively minor, uncertainty increases substantially around 2080 (Church et al. 2013) and should be appropriately and transparently accounted for in planning and design (Stephens et al. 2017) in order to avoid an underestimation of flood risks (Ruckert et al. 2017).

Infrastructure development decisions often come with long-term commitments that can be climate sensitive (Hallegatte 2009). For example, the engineered design life of port structures is typically 30-50 years (depending on the type of structure), but these structures will often remain in service for 80-100 years (Becker et al. 2015; Taneja et al. 2012; UNCTAD 1985). Thus, many structures designed and built today will face different environmental hazards and risk levels in 2100 . However, a survey of port administrators (Becker et al. 2012) found that capital planning cycles at ports are typically only 5 to 10 years. The mismatch between planning, infrastructure working life, and uncertainty in future environmental conditions presents unique challenges for port planning (Becker et al. 2012). 
A 2012 survey conducted by the American Association of Port Authorities (AAPA) showed that U.S. ports planned to spend at least $\$ 46$ billion in improvements and upgrades through 2016 (AAPA 2012). Remarkably, due to a projected increase in shipping combined with the need to replace aging infrastructure, a follow-up port infrastructure investment survey in 2016 found that U.S. ports plan to spend nearly $\$ 155$ billion in port-related improvements and upgrades through 2020 (AAPA 2016). This shows that infrastructure spending from 2016-2020 is expected to triple that of 2012-2016. While portions of this investment will be dedicated to dredging and navigational improvements, the 2016 survey found that key investments are being planned for terminals, berths, piers, equipment, expansion, facility rehabilitation, and road and rail connections (AAPA 2016).

Seaports and port infrastructure will be especially vulnerable to SLC because they do not have the option to relocate, as their functionality depends on their coastal location (Asariotis and Benamara 2012). Researchers predict that rising sea levels will affect 79 European ports by 2100 (Christodoulou et al. 2018). Officials from the Port of Virginia are expecting a sea level rise increase of a foot and a half within the next 30 years, triggering them to invest in raising electrical power stations and moving data servers farther away from the water's edge (Phillips 2019). Changes in sea level will also have a direct effect on other coastal hazards such as storm surge (Neumann et al. 2015), which adds to the importance of making planning decisions based on the best available sea level rise science.

\section{$\underline{\text { SLC uncertainty challenges engineers }}$}

Ports provide both private-sector profits and public services, resulting in a wide variety of stakeholders that extend beyond shipping companies, insurers, local governments, and local residents. Thus, maritime engineers and designers must consider not only their clients' needs, but also the needs of other stakeholders dependent on port services (Becker et al. 2015). The inadequate design of port infrastructure can result in negative consequences for these stakeholders, including indirect damage to economic supply chains or environmental damages (Becker et al. 2013). The uncertainty of regional SLC projections over the design or working life of port infrastructure can challenge engineers to make appropriate design 
decisions. Furthermore, changes in the local geomorphology due to climate change can add to that uncertainty (Becker et al. 2015). The standards, codes, and regulations that govern infrastructure design are typically slower to respond to such changes (Olsen 2015). This adds to the difficulty of answering the primary question: What level of SLC should maritime infrastructure engineers design for?

\section{Industry efforts address the risks of SLC}

Federal agencies recognize the need to incorporate climate change and coastal hazard factors such as SLC into infrastructure design, but most design changes occur for structures that are being rebuilt after being damaged or completely destroyed (Savonis et al. 2014). Both the U.S. Army Corps of Engineers (USACE) and the Environmental Protection Agency (EPA) have advocated that SLC be incorporated in the design of all federally funded projects, thus far however, the U.S. has adopted no mandates or policies to this effect (Headland et al. 2011). In 2015, the Obama administration issued Executive Order 13690 which proposed a new Federal Flood Risk Management Standard (FFRMS) which required federally funded infrastructure projects to utilize one of three design alternatives: use data and methods informed by best-available science, build two feet above the 100-year flood elevation, or build to the 500-year flood elevation [80 Fed. Reg. 13690 (January 30, 2015)]. The FFRMS would have ensured that federally funded structures were designed for future climate hazards. The Trump administration in 2017, however, issued Executive Order 13807 revoking Obama’s Executive Order 13690 [82 Fed. Reg. 13807182 (August 15, 2017).].

Numerous federal agencies such as U.S. Department of Transportation Federal Highway Administration (FHWA), USACE, and the National Oceanic and Atmospheric Administration (NOAA), along with state and local governments, have developed SLC guidance. However, they use different scales, projections, and uncertainties of SLC (FHWA 2012; NRC 2012; OPC-SAT 2018). USACE has published technical guidance for adaptation to SLC (USACE 2014) and developed publicly available tools such as the Sea-Level Change Curve Calculator and the Sea Level Tracker. The Sea-Level Change Curve Calculator offers a way to visualize the USACE and other SLC scenarios for specific locations in 
the U.S. based on NOAA tide gauge data. Furthermore, the COMET Program has recently produced an online educational tool that introduces the Sea-Level Change Curve Calculator and how it can be applied to scenario-based planning for SLC (COMET 2019). In addition to providing information on USACE resources, the lesson also presents NOAA's sea level trends and the NOAA Sea Level Rise Viewer where engineers and designers can access site-specific projections (COMET 2019).

Several industry leaders are also developing tools, updating guidance, and investing their resources into helping ports become more resilient. The American Society of Civil Engineers (ASCE) Ports and Harbors Committee published recommendations to assist port and maritime infrastructure engineers navigate the difficulties of designing structures for SLC (Becker et al. 2015). ASCE's Committee on Adaptation to a Changing Climate also published a manual of practice on the design of climate-resilient infrastructure (ASCE 2019). With so many tools, guidelines, and information sources, this research ascertain what information the engineering community utilizes and how strong of a link exists between coastal hazards research, implementing research into design and port operations.

\section{$\underline{\text { Methods }}$}

An online survey was developed to target engineers from consulting firms, port authorities, and government agencies with experience working on U.S. port infrastructure projects.

\section{Survey distribution}

The sample approach focused primarily on members of ASCE's Coasts, Oceans, Ports, and Rivers Institute (COPRI). Participation was voluntary, and no compensation was provided. The Institutional Review Board (IRB) of the University of Rhode Island approved this study. In September 2018, the researchers distributed the survey to all members of COPRI's Ports and Harbors Committee through SurveyMonkey, an online service for conducting surveys. This approach allowed the researchers to costeffectively reach engineers and designers across the U.S. COPRI also included a link to the survey in their October 2018 newsletter and the link was shared in the "Environmental, Coasts, Oceans and Water 
Infrastructure" forum within ASCE Collaborate. It was also posted to the Coastal List (Center for Applied Coastal Research 2019) and shared through LinkedIn. Furthermore, a snowball sampling approach (Atkinson and Flint 2001) encouraged survey recipients to distribute the survey throughout their own professional networks. The survey distribution plan helped achieve a robust sample size that represents practicing port and maritime infrastructure engineers in the U.S.

\section{$\underline{\text { Online survey instrument }}$}

The online survey instrument was created with input from a five-person project steering committee consisting of members from COPRI's Sea Level Change Subcommittee. Steering committee members were all Professional Engineers working in the U.S. port industry, and therefore fit the survey target population criteria. This helped to ensure the survey questions were appropriate for their colleagues in the industry. Steering committing meetings were convened throughout the development of the survey to capture the expertise of those on the steering committee and receive guidance on questions to ask and response options to those questions. Prior to distributing, an additional five members of the Ports and Harbors Committee (i.e., retired professional engineers, engineering professors, and regulatory engineers) pilot tested the survey to further vet the language of each question and the response options. The 20 -item survey was designed for practicing engineers in the U.S. and estimated to take 10-15 minutes to complete (see Fig. S1 for survey instrument). The survey was broken down into four sections, as follows:

- Respondent Profile and General Information asked questions regarding level of experience with port infrastructure projects and the type of organization the respondent works for.

- Sea Level Change Design Considerations assessed the capacity at which projects that respondents have played a role in have incorporated SLC and explored specific details regarding their experience, such as types of structures respondents work on and the geographic locations they have engineering experience in.

- Incorporating Sea Level Change into Design explores how SLC is incorporated into design and the design decisions being made at the engineering level. 
- Not Incorporating Sea Level Change into Design asked about potential barriers to incorporating SLC and personal support or opposition to incorporating SLC into design.

Nine out of the 20-items are presented in this paper in order to answer the three research questions. The nine questions are as follows:

- In the past 5 years, about how many port infrastructure projects have you played a role in engineering and/or designing? (Q6);

- Of the port infrastructure projects you have worked on over the past 5 years, about how many have incorporated sea level change? (Q7);

- For which types of structures does your organization incorporate/consider sea level change during the design phase? (Q8);

- Does your organization use a policy/planning document that communicates how future sea level change should be incorporated into port infrastructure design projects? (Q10);

- What factors cause your organization to add a sea level change design component to a project? (Q12);

- When incorporating future sea level change into the design of port infrastructure, where does your organization obtain sea level change projections from? (Q13);

- How confident are you in the accuracy of the sea level change projections that are being incorporated into projects your organization designs? (Q14);

- In cases where sea level change is not incorporated into the design of port infrastructure projects, what are the potential reasons why? (Q17);

- From the list above, what are the three most common reasons why sea level change may not be incorporated into a project? (Q18). 


\section{$\underline{\text { Data overview }}$}

In total, 118 responses to the survey were received, and 85 of the responses were useable. Of the 118 responses received, 12 respondents indicated having no professional engineering and/or design experience working on port infrastructure projects, and there were 21 responses with no questions answered for the final three of four sections of the survey. Therefore, those 33 responses were excluded. Partially complete responses, however, were included in the analysis. Some highlights of the responses follow:

- 60 respondents worked for private design consulting firms

- 16 respondents worked for port authorities

- $\quad$ nine respondents worked for government agencies

- Of the 85 responses, 62 respondents voluntarily provided the name of the organization they worked for. Of these:

○ 31 different private consulting firms were represented

- Nine private consulting firms had more than one respondent from their firm:

- six firms had two respondents,

- two firms had three respondents,

- one firm had four respondents.

○ 11 different port authorities were represented

- $59 \%$ of respondents had over 15 years of experience

- $81 \%$ self-identified as a project manager or someone who makes final design decision on projects at their organization

- $54 \%$ indicated having professional experience in more than one geographic region.

- The region with the greatest number of respondent experience was the Gulf Coast (42), followed by Alaska (38), then the Southeast (36) and Mid-Atlantic (36), Northwest (33), Southern California (31), Northern California (30), Northeast (26), Hawaii (20), and with the least respondents, Great Lakes (18). 


\section{$\underline{\text { Results and Discussion }}$}

The results and discussion section describes survey respondents' perceptions of the state of the practice for designing port infrastructure for SLC, including organizational policies, sources of scientific data on SLC, SLC implications for design life, and reasons that projects do or do not consider SLC. This section uses the results of the survey to provide evidence addressing the three research questions.

$\underline{\text { In what capacity are port infrastructure designers incorporating a SLC projection into their }}$ design specifications for large-scale port engineering projects?

This overarching question aimed to identify the current level at which engineers consider SLC and to produce baseline data to track how the state of the practice changes in the future. Respondents were asked the total number of port infrastructure projects they worked on in the past five years (Q6) and the number of those projects that had incorporated SLC (Q7). On average, respondents played a role in designing 11.1 (SD: 9.9) port infrastructure projects in the past five years. Further analysis suggests that on average, $43 \%$ (SD: 39\%; Median: 30\%) of port infrastructure projects that respondents worked on over the past five years have incorporated SLC. Because engineers with more SLC design experience may have been more likely to respond to this survey and skew the results, $43 \%$ may not be an accurate nationwide indicator of the capacity in which port infrastructure design incorporates SLC. It is likely that $43 \%$ is optimistic due to the potential sample bias.

To explore how organizations approach SLC design, respondents were asked if their organization has a policy or planning document that communicates how future SLC should be incorporated into port infrastructure projects (Q10). As shown in Figure 1a, 64\% of respondents indicated that their organization did not have a policy or planning document, with only $29 \%$ having a document, and of those respondents, $9 \%$ use it for all projects, $16 \%$ use it for only some projects, and $4 \%$ use it rarely. The remaining $7 \%$ were unsure whether their organization had a SLC design document.

The responses to this question were then used to assess whether or not having a policy or planning document (Q10) had an effect on the number of projects that incorporated SLC (Q7) (Figure 
1b). There were 25 respondents (18 of which represented private consulting firms) in the "Have Policy Document" group and 60 in the "Don't Have Policy Document or Not Sure" group. Within each group, the average percent of SLC incorporated projects that respondents worked on in the past five years was calculated. A difference between the two groups was found where the average percentage of projects that have incorporated SLC is $30 \%$ higher for respondents that work for an organization with a policy document (Mean: 65\%; SD: 35\%; Median: 67\%) than those who do not (Mean: 35\%; SD: 36\%; Median: $20 \%)$.
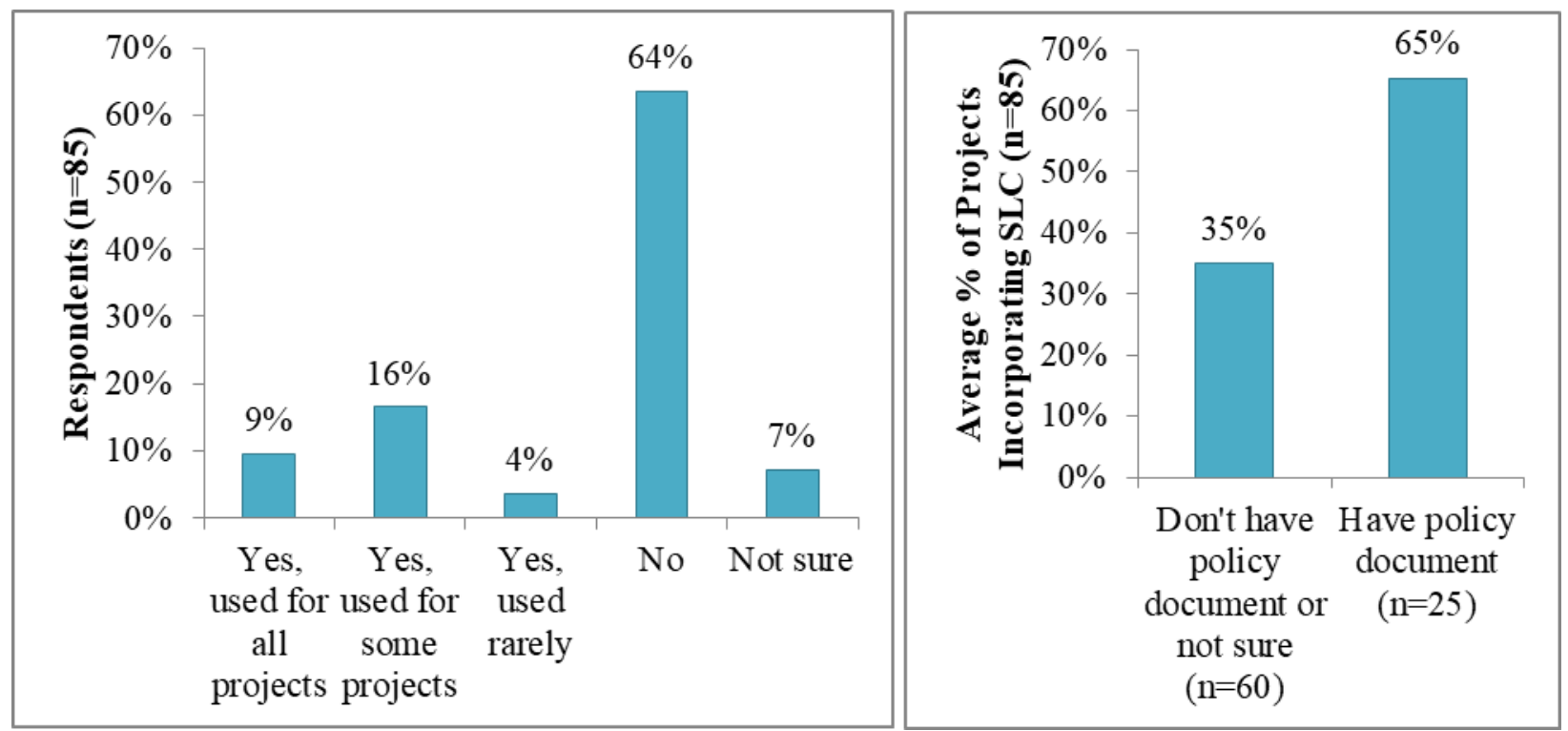

Figure 1. a) Utilization of a policy document that guides SLC design decision making. b) Effect of a policy document on the frequency of incorporating SLC into design.

Perhaps engineers working at organizations with a formal document have received training or other information about how to make decisions on designing for SLC, which allows them to recommend design changes to a client or an in-house design team. Formal policies or documents can lend credibility and provide the basis for recommendations. Conversely, engineers without the documented support from their organization may be less willing to take the personal and professional risk that comes with making subjective decisions. If an organization has not developed a formal policy or guidance document, its staff 
engineers may be less likely to incorporate SLC in their structure designs as they may not have the necessary protocols or tools to do so.

Having a policy or planning document at the organization level could also become a selling point for the organization in competing with other private consulting firms for a contract. Port authorities are beginning to require SLC considerations in the design and redesign of port infrastructure more frequently. In 2018, for example, the Port Authority of New York and New Jersey (PANYNJ) sent out a request for proposal (RFP) for the replacement of numerous wharf structures, which required the bid to provide best practice wharf design concepts that take into account sea level rise (PANYNJ 2018). As these projects and practices become more prevalent, private consulting firms that have a clear and specified approach to designing for SLC could have a market advantage.

Researchers also examined the capacity in which SLC was incorporated across different types of port infrastructure projects (Q8). Respondents were asked how frequently their organization considers and/or incorporates SLC into the design of 17 different types of port infrastructure. To make comparisons between structure types that are similar in functionality, the 17 infrastructure types were grouped into six different subgroups: protection structures, berthing structures, cargo storage structures, connectivity infrastructure, electrical and operations, and water flow structures.

Figure 2 shows how often respondents believed their organization incorporates SLC for each structure type. The researchers grouped responses into three frequency categories. The y-axis shows the percentages of responses for each category. The structure type is on the x-axis, and the number of respondents with design experience for each structure type (n) is indicated in parenthesis next to or below the structure type. 

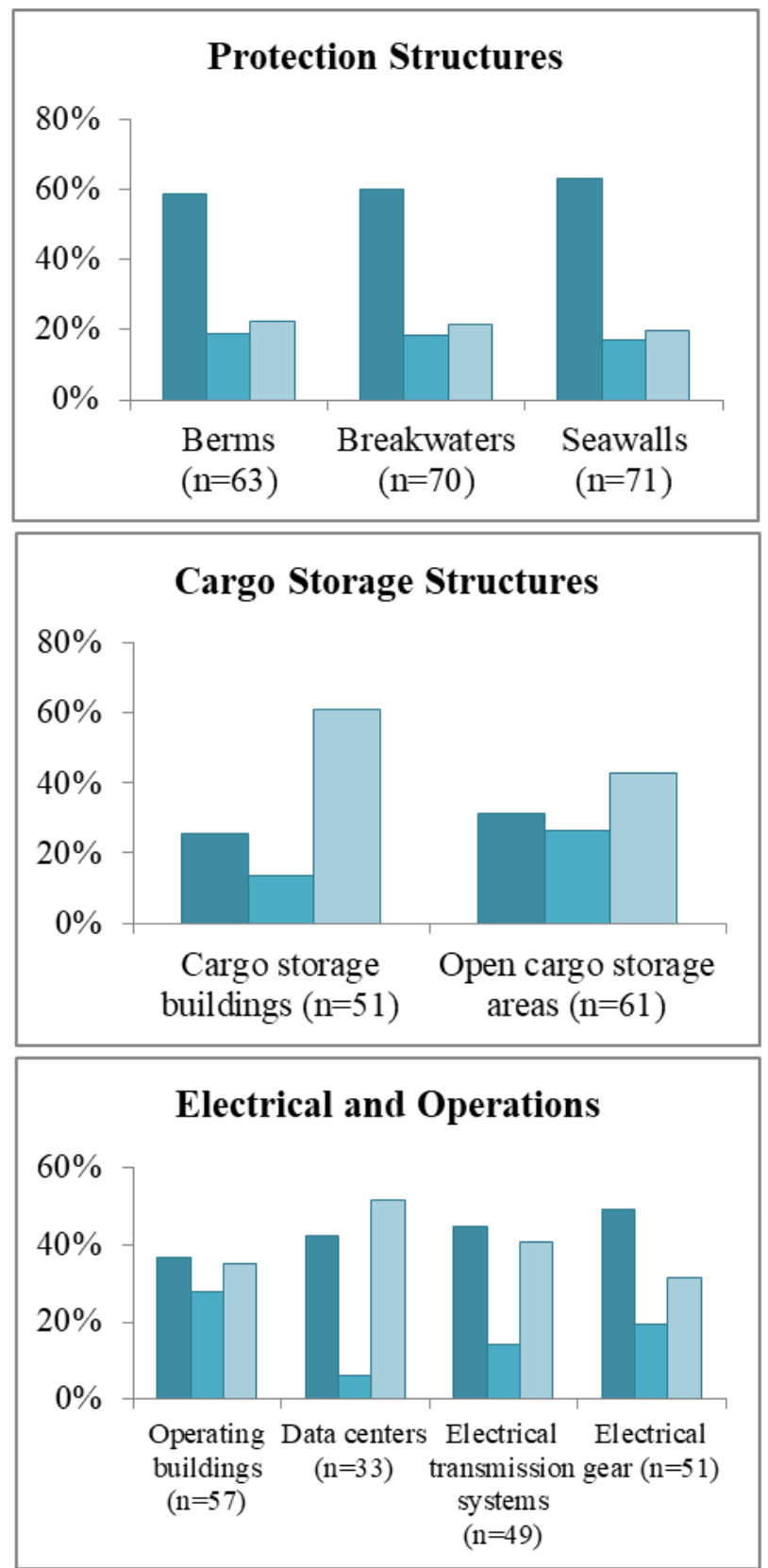
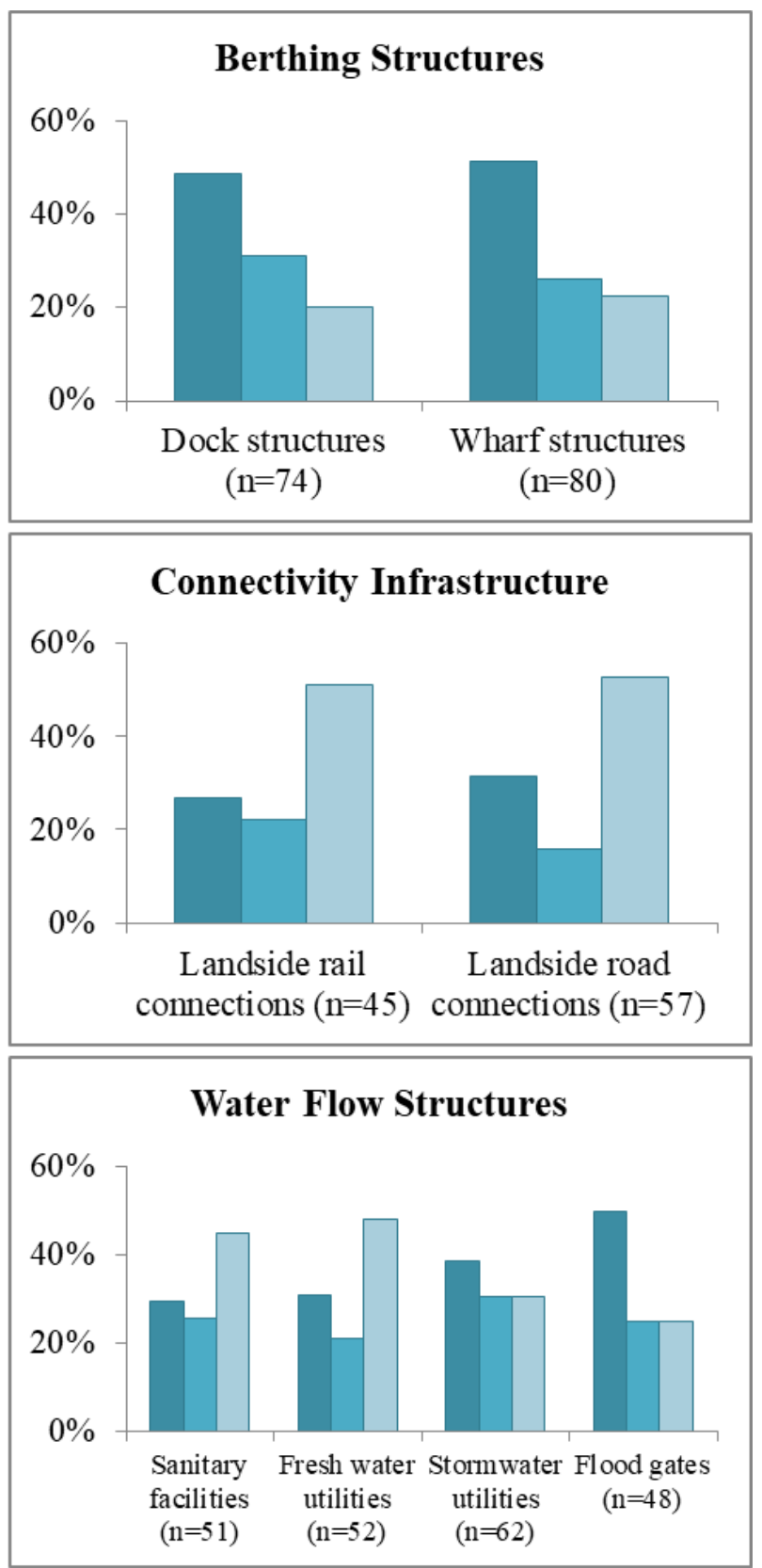

\section{$\square$ Always/Often $\quad \square$ Sometimes $\quad \square$ Never/Rarely}

Figure 2. Structure types which respondents acknowledged incorporating SLC during design.

Structure types that are the closest to, and in most cases directly abutting, the waterfront had the highest percentage of either always or often incorporating SLC in their design. This applies to Protection Structures (berms, breakwaters, and seawalls) and Vessel Berthing Structures (dock structures and wharf structures). Conversely, port hinterland connections such as roads and railways, which are typically 
located further away from the waterfront, had two of the four highest percentages for either rarely or never incorporating SLC. Understandably, these findings suggest that the closer to the water a structure is located, the more likely the design of that structure will incorporate SLC.

Where do incentives and disincentives originate for U.S. engineering firms to incorporate SLC into the design specifications of large-scale port engineering projects?

First, this section discusses the variety of factors that can act as an incentive to incorporate SLC and how the decision can originate from several different stakeholders. Conversely, for projects that do not incorporate SLC, this section then addresses the disincentives that prevent engineers from incorporating SLC and how the development of regulatory design standards can alleviate several barriers identified by respondents.

\section{Incorporating SLC into design is motivated by a variety of factors}

To better understand the motivations and driving forces that lead to engineers designing port infrastructure for SLC, respondents were asked about the factors that cause their organization to add a SLC design component to a project (Q12). Since the decision to incorporate SLC could originate from any or even a combination of the factors presented for any given project, respondents were asked to indicate how often each factor plays a role in causing SLC to be incorporated into a project (Figure 3). 


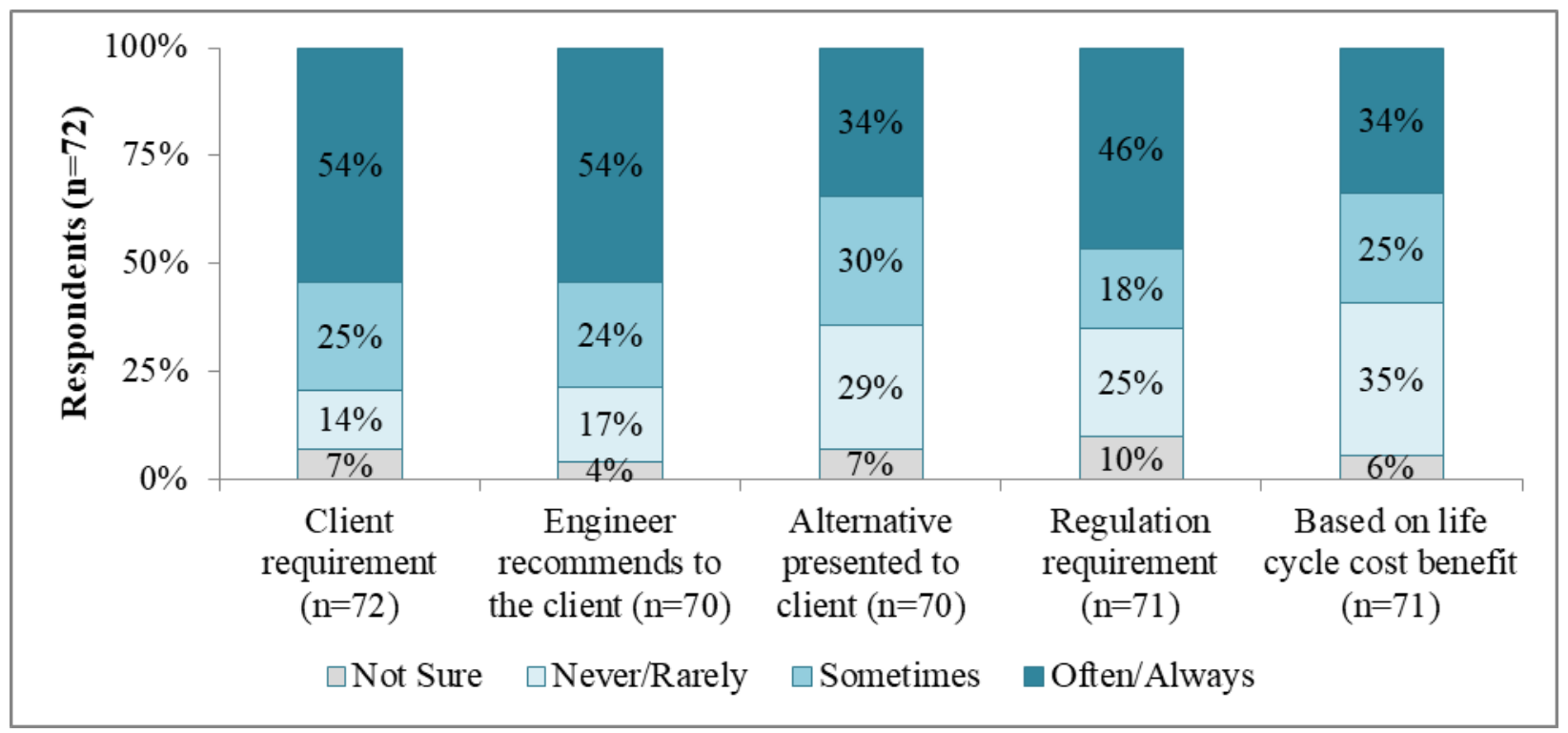

Figure 3. Potential factors that may cause engineers to incorporate SLC into design specifications.

Client requirements, engineering recommendations, and regulation requirements were the three leading factors that respondents suggest drive the incorporation of SLC in port infrastructure design. However, the Often/Always group had the highest percentage of respondents for four out of the five factors listed. Incorporating SLC based on a life cycle cost/benefit analysis was the only exception where Never/Rarely (35\%) was the most common response by $1 \%$ over the Often/Always group (34\%).

Simplifying the five factors listed, one factor is client dependent (Client requirement), one factor is regulatory dependent (Regulation requirement), and the other three factors are decided by engineers (Engineer makes recommendation to the client, Design alternative presented to the client, and SLC is incorporated based on life cycle cost/benefit analysis). Responses to this question suggest that none of the three groups are leading the effort to incorporate SLC. Furthermore, responses suggest the decision to incorporate SLC could originate from different stakeholders from project to project.

Although there were only slight variations in the responses, and there were no factors that stood out as being the least likely driver of SLC consideration, Incorporating SLC based on a life cycle cost/benefit analysis had the greatest percentage of respondents that said it was either Never or Rarely a driving factor. Perhaps engineers are not conducting a life cycle cost/benefit analysis, which would 
indicate a lack finances or incentives to execute long term planning, or engineers are conducting a life cycle cost/benefit analysis, but the results of the analysis suggest it would be more cost effective to ignore SLC. Further investigation into the use of life cycle cost/benefit analysis, long term planning from the engineering perspective, and design life challenges would shed more light on why this particular factor appears to play a very limited role in the decision to incorporate SLC into port infrastructure design. Additionally, although regulation was only the third most common factor, it is possible that regulation may be the leading factor in some geographic regions, such as California ("State of California Sea-Level Rise Guidance" 2018), but a non-existent factor in other regions, such as the Gulf Coast. The survey could not definitively answer this question because more than half (54\%) of the respondents reported having engineering experience in multiple geographic regions, and therefore, responses to other questions could not be linked to specific locations.

To gauge how engineers determine the level of SLC they need to design for, respondents were asked from where their organization obtains SLC projections (Q13) (Figure 4). As previously mentioned, numerous organizations have produced SLC projections with varying rates, largely due to the uncertainty of SLC projections. Therefore, engineers must make decisions on which projections they will rely on. According to respondents, the most frequently used source of SLC projection data was NOAA (65\%), followed by USACE (49\%). Although the third most commonly used source was state or local organizations (40\%), there were an equal percentage of respondents who rarely or never use state or local projections (40\%), which could point to the fact that not all states have developed SLC design guidance specific to their coastline. For five out of the seven sources shown in Figure 4, at least half of the respondents indicated either sometimes, often, or always using that particular source. Therefore, outside of the fact that NOAA and USACE are the most relied upon sources, these findings highlight that there is very little, if any, standardization across the approach taken by different engineers to incorporate SLC into design. It appears that any one engineer could use a different SLC projection for any particular project. This highlights the impact that the uncertainty of SLC rates has on the design process. 
Uncertainty is the ultimate reason that there are various sources with differing projections, and therefore, consistency across planning for SLC is difficult to achieve.

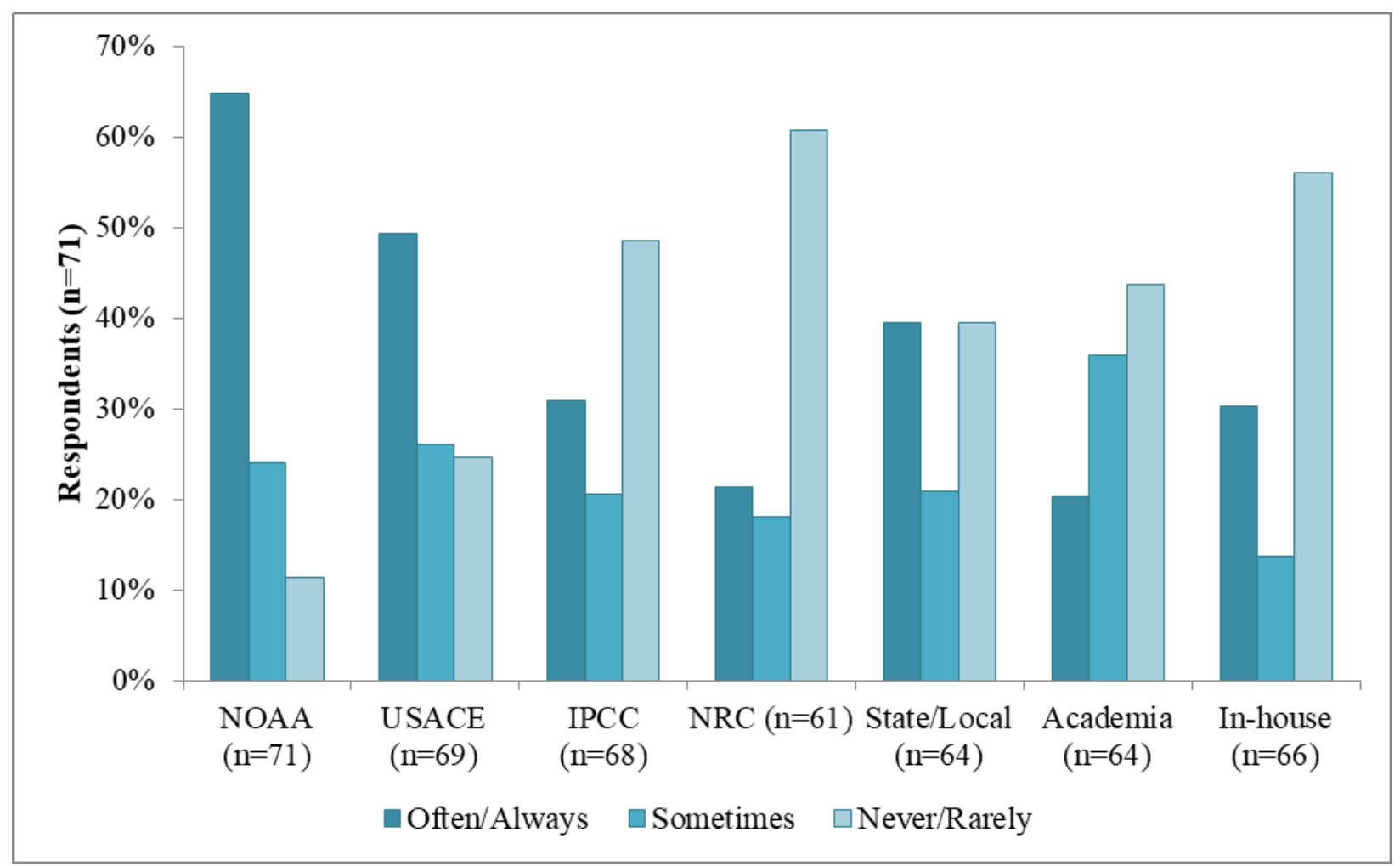

Figure 4. Utilization of different sources of SLC projection data.

For each of the possible sources of SLC data, respondents were asked how confident they were in the accuracy of the SLC projections that are being incorporated into projects that their organization designs (Q14). Not only are NOAA and USACE the most relied up sources to obtain SLC data, they are also the sources that respondents were the most confident in (Figure 5). In general, respondents were relatively confident in the accuracy of projections from all of the sources listed. For each SLC projection source identified, $12 \%$ or less of respondents reported little or no confidence in the accuracy of projections. 


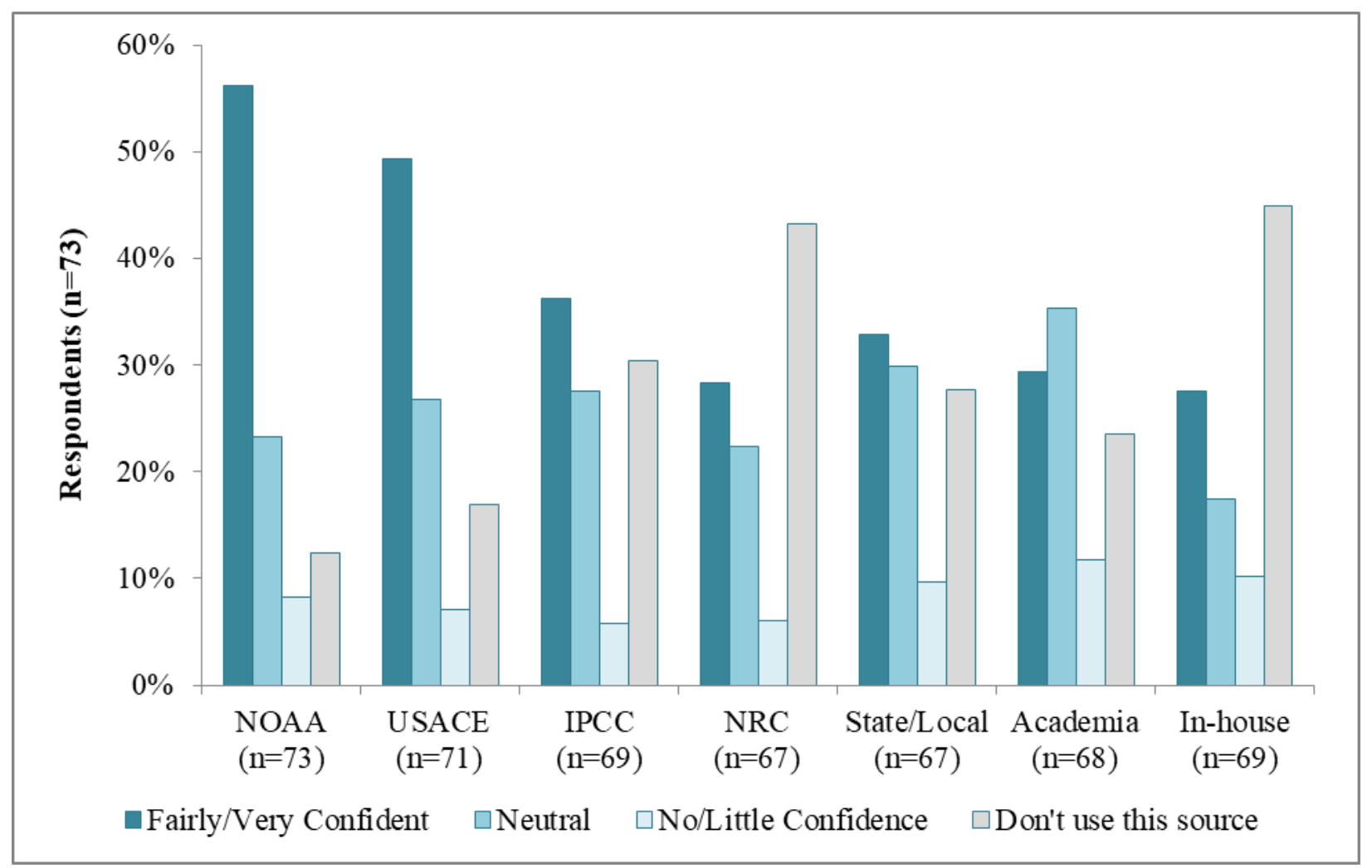

Figure 5. Confidence in the accuracy of SLC projection data from different sources.

\section{Lack of design standards were a key barrier to incorporating SLC into design}

The online survey asked respondents to select which of 14 potential barriers (derived from previous studies and input from the ASCE experts) they have encountered during their professional career (Q17 and Q18). Becker et al. (2015) address the lack of nationwide guidance, and Stephens et al. (2017) discusses the challenges of dealing with uncertain SLC projections. As previously mentioned in the Methods section of this paper, the researchers established a five-person project steering committee consisting of members from COPRI's Sea Level Change Task Committee that were influential in developing this list of potential barriers.

Of the 70 respondents to this question, 36 indicated that having no standards was a reason for not incorporating SLC. A lack of project funding and the client not wanting to incorporate SLC were tied as the second most commonly acknowledged barriers. Not surprisingly, too much uncertainty with SLC projections was also perceived as a top five barrier. Furthermore, 17 of the respondents indicated that 
there were other barriers that they felt prevented SLC from making it into final design which were not included in the response list within the survey. Other barriers included site constraints, operational implications (e.g. raising certain structures for future conditions renders them unusable during current tidal conditions), and difficulty incorporating SLC for retrofit, rehab, and upgrade projects on structures that were not originally designed for SLC. Figure 6 shows that every barrier listed as a response option was seen as a potential barrier by at least 10 respondents. These findings suggest engineers felt that numerous barriers prevent SLC from being incorporated into design.

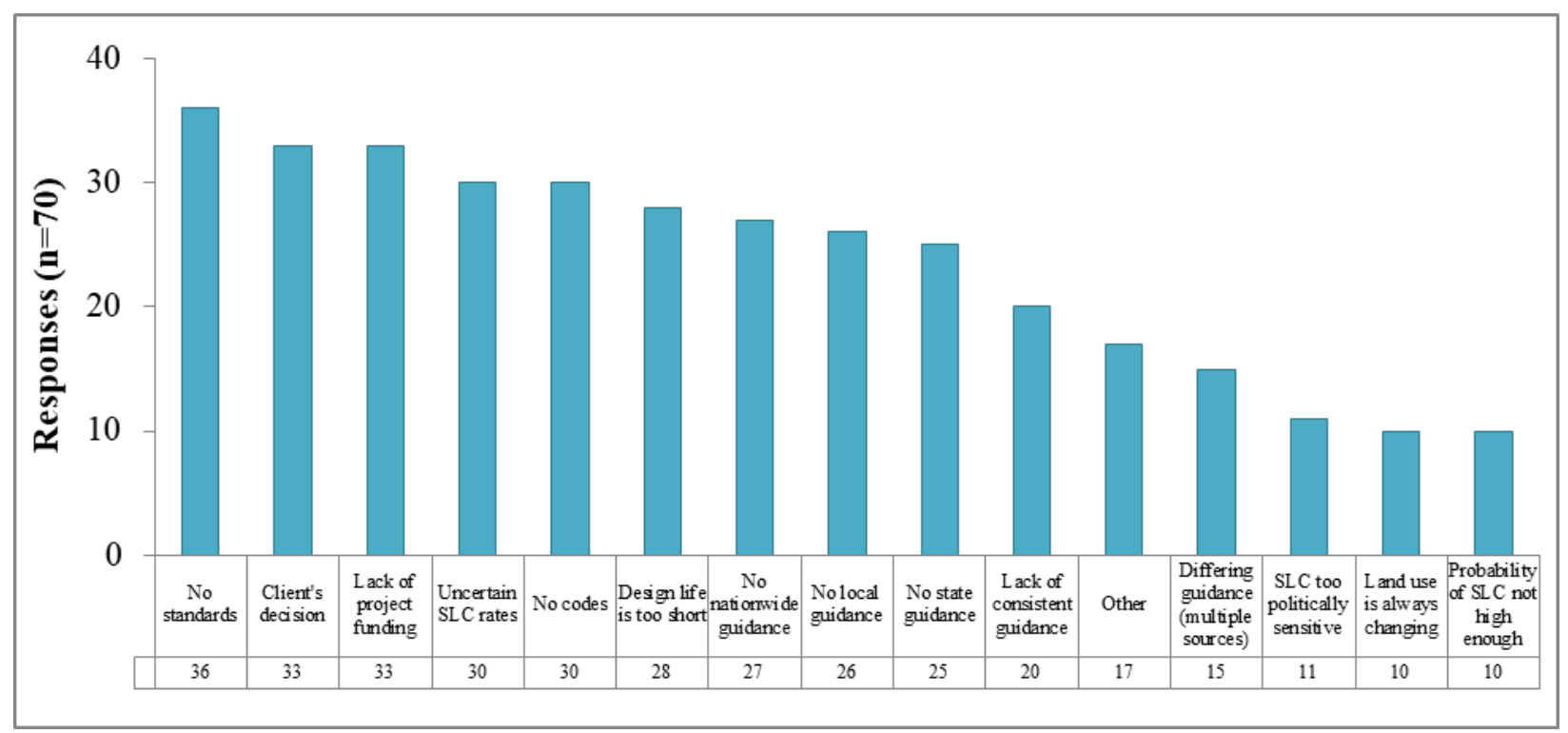

Figure 6. Potential reasons why SLC may not be incorporated into the design of port infrastructure.

Over half of respondents (36) selected the barrier No Standards. Regulatory standards and codes remove the burden on engineers to make subjective SLC design decisions. This barrier also renders many of the other 13 barriers less relevant. For example, design standards would override a client's decision to ignore SLC. Survey respondents reported the client input as a primary driver in the decision to incorporate or ignore SLC. The survey results suggest that clients hold decision making power, but design standards can provide consistency in SLC design specifications and requirements. Additionally, Lack of project funding would no longer hinder the incorporation of SLC. One respondent noted, "Lack of 
planning or vision for surrounding facilities being modified for sea level change has caused accommodating for sea level change to be the first item removed from scope of project to meet funding." When funding is limited, SLC can be low on the priority list. However, as another respondent indicated, removing SLC from the scope of a project would not be an option if there are regulatory design standards in place, stating, "The cost differential cannot be justified, especially when it is not a regulatory compliance issue."

As previously mentioned, federal regulation has had some success under Executive Order 13690, establishing the FFRMS. Until it was revoked by President Trump in 2017, the FFRMS provided clear flood protection requirements for designing infrastructure. Although SLC is projected to be highly varied across coastal regions of the U.S., the FFRMS provided flexibility and allowed owners and engineers to select from multiple options to build for resilience. This flexibility alleviates some of the financial stress by not forcing a specific action onto an owner. Of course, some ports have a greater institutional capacity to cope with these requirements, but providing different options minimizes any strategic advantage one port would have over another when requiring all U.S. ports to address increased flood risk.

What strategies are port infrastructure designers implementing to cope with the scientific uncertainty of SLC?

The third and final question sought to understand what engineers are currently doing to address SLC in their practice. Some respondents indicated designing port infrastructure in a way that can accommodate future upgrades to keep pace with SLC, but results ultimately suggest that SLC uncertainty has not been a major consideration due to relatively short design lives, for which uncertainty is not as significant as it is toward the end of the century. Therefore, strategies to cope with uncertainty have not been widely developed or implemented.

From Figure 7, respondents perceived the client not wanting to incorporate SLC (count=14) as the most common barrier. Design life not extending far enough into the future to consider SLC was the second most common barrier (count $=8$ ). This suggests that since these structures are determined to have 
relatively short design lives, the projected sea levels at the end of their design lives are not significant enough to warrant incorporating into design specifications. However, respondents also commented on the difficulties of incorporating SLC for retrofit, upgrade, or expansion projects that involve structures not originally designed for future SLC. As one responded stated, "The biggest hurdle is in retrofit wharf construction. The costs are prohibitively huge to raise marine deck structures." Another wrote, "So much of the work is retrofit of existing docks that generally it doesn't make financial sense to raise." And a third reported, "It is hard to accommodate significant sea level rise with existing large marine terminals (multiple thousand feet of wharf, 200+ acres, rail, etc.) - it is not financially feasible." This raises attention on how new infrastructure is designed, and highlights the importance of new infrastructure incorporating SLC. Alternatively, proper consideration of long-term resiliency planning during design can ensure that the structure is able to be augmented throughout its service life and avoid retrofit challenges that survey respondents are currently facing. Furthermore, these findings call into question port planning time frames and the rigid methodology of designing structures for a specified lifetime or "design life" rather than the structure's "service life" (Figure 8).

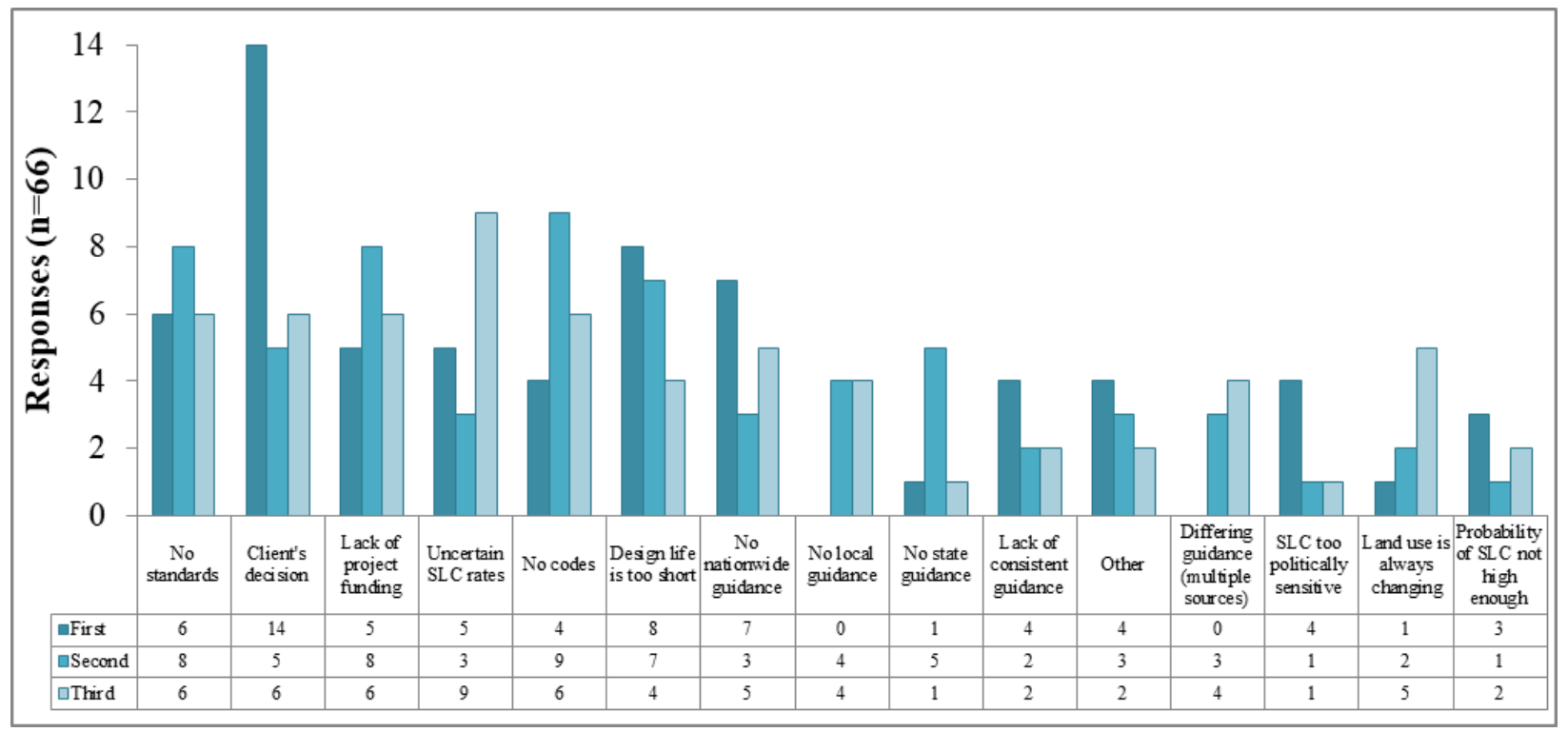

Figure 7. Perceived most common reasons why SLC may not be incorporated into design. 
Design life of port infrastructure varies depending on structure type, but typically ranges from 3050 years. However, it is not uncommon for some port infrastructure to have service lives that exceed 100 years (Becker et al. 2015). This is a concerning disconnect when designing port infrastructure for SLC. For example, new infrastructure designed for the projected sea levels of 2050 could likely remain in service beyond 2050. Therefore, the design may be inadequate for the change in sea level between 2050 and the end of its service life. Alternatively, the structure could be repaired, retrofit, or upgraded at the end of its design life, but as respondents said, it is often more difficult to design for higher sea levels after initial construction. The significant uncertainties in SLC rates combined with the uncertainties of service life make designing for SLC challenging. Nevertheless, designing port infrastructure for a theoretical design life hinders the opportunity for ports to be more resilient in the future.

Design Life - The theoretical period of time during which engineers expect a structure to be fully operational.

Service Life - The period of time in which the structure is actually in use, from construction completion to failure.

Figure 8. Definitions of "design life" and "service life" for infrastructure.

\section{$\underline{\text { Recommendations }}$}

Findings suggest that to improve the resilience of port infrastructure in the long term, the engineering community needs to reconsider traditional engineering practices that involve designing for a specific design life. In planning, flexibility can bridge the gap between what is known and what should be known (Faludi and Hamnett 1977). However, engineers and designers have traditionally assumed that natural systems fluctuate within an unchanging envelope of variability, also known as stationarity (Milly et al. 2008). Flood analysis, for example, utilizes the extent and intensity of historical flooding events in order to generate flood exceedance probabilities (Merz and Thieken 2004). The method applies a flood frequency analysis to a dataset of discharge data (Stedinger et al. 1993) and transforms the associated 
discharge to defined return periods (e.g., the 100-year event) with an estimated inundation extent and depth (Apel et al. 2009). With climate change, storm frequency, duration, and intensity will likely change, meaning that the range of future flooding can no longer be predicted based only on observed changes in Earth's climate (Milly et al. 2008). Even small climatic changes may result in large changes in storm intensities or patterns (Knox 2000). This new paradigm led Milly et al. (2008) to assert that "stationarity is dead" and can no longer serve as a default and central assumption for risk assessment and planning. A shift in planning, engineering, and design approaches is necessary to increase resilience in the built environment (Ahern 2011). As such, two major recommendations emerged from this research project and are described in the next sections.

\section{Undertake Life Cycle Cost Analysis that includes SLC}

Successfully addressing SLC and other climate related design variables will not come with a "one size fits all" solution for every critical piece of port infrastructure and every project site. Different types of port infrastructure have unique characteristics that may impact how engineers factor SLC into the design. For example, fixed wharves and piers have a very different intended use and importance compared to bulkheads and breakwaters, and therefore, design considerations, guidance, and standards should adhere to those differences. Similarly, each project site has a different set of conditions that SLC will have a unique impact on. Thus, engineers may require a greater reliance on site-specific hazard assessments in the future that evaluate flood risk, tolerance to flooding, and hydrodynamic forces on under deck elements in the case of fixed wharves and piers. Site-specific assessments, based on the best available science, can then lead to the effective utilization of Life Cycle Cost Analysis (LCCA).

Engineers with expertise in other disciplines often rely on LCCA when designing for climate impacts. ASCE's Structural Engineering Institute (SEI) advocates for the use of LCCA design practices by stating, "Structural engineering is undergoing a profound change towards a life-cycle oriented design philosophy where the classical point-in-time design criteria are extended to account for more comprehensive time-variant performance indicators over the entire service life" (Biondini and Frangopol 
2018). A study conducted by ICF International, Inc. also highlights the benefits of this approach where the authors support LCCA by asserting, "This methodology can be used to support decision making regarding climate change adaptation alternatives under compounded uncertainty. In addition, this methodology can be used to determine which adaptation design alternative is the most consistently resilient across the range of climate change and disaster event scenarios" (Rodehorst et al. 2018).

LCCA can clearly be effective in navigating the challenges of designing for SLC, but results of this survey suggest there is limited use of this methodology. When failing to consider the entire service life of a structure, along with the anticipated rehab and retrofit actions needed throughout its service life, engineers run the risk of underestimating the height required for a structure to cope with future SLC. In some scenarios, engineers could conduct an LCCA on a structure, but still select a lower water level to design to. In those scenarios, the benefit of the LCCA is that it would require analysis of future SLC above the selected water level to determine its future resiliency and potentially lead to a design that can be easily upgraded in the future. Additionally, SLC design considerations are not limited to structure elevations, and should not be the sole focus of an LCCA. For example, SLC will also have an impact on the hydrodynamic forces on under deck elements, which could be more important than water level at some project sites. To determine which design variables have the greatest influence over the structure's resilience, a site-specific assessment is a critical information gathering process that will better inform an LCCA.

\section{$\underline{\text { Collaborate to create new design standards and guidance }}$}

The inconsistencies in approaching SLC design challenges and the lack of SLC design standards highlighted in this paper calls for collaboration among the engineering community, port authorities, and regulating bodies to improve the resilience of port infrastructure. Developing design standards collaboratively can help engineers overcome the barriers that currently prevent them from incorporating SLC. With design standards in place, many of the other barriers acknowledged by respondents would no longer exist. Therefore, further exploration and discussion is required to determine the most effective 
approach to implementing design standards. Should regulation be implemented at the federal level? Should states be the ones to develop their own design standards? Should standards be applied based on design life? Should standards be specific to the type of infrastructure? These questions deserve further dialogue as SLC becomes an increasing threat to port infrastructure. Also, the opportunity exists for private consulting firms that have a policy or planning document for SLC design to share resources, tools, and best practices with other members of the engineering community. Organizations such as ASCE have proven to be great facilitators of this type of knowledge sharing. Given the massive amounts of infrastructure spending that ports are planning in the next five years, ensuring that these investments are sustainable and resilient to future coastal hazards should be a top priority.

Reestablishing the FFRMS would be a positive approach toward improving the resilience of seaports nationwide. However, as discussed earlier, the concept of stationarity and utilizing 100-year flood or 500-year flood events to guide design is an outdated one. Due to climatic changes, the return period probability for storm events is no longer what it once was. The entire globe is witnessing more intense storm events and more frequent high intensity storms, so it can no longer be accurately predicted what a 100-year storm brings in terms of flood extent and depth.

ASCE has a unique role to play in the development and improvement of regulatory standards and codes. ASCE has proven to be a leader in the development of flood resistant design standards though ASCE/SEI 24-14 (ASCE 2014). ASCE 24 is the industry standard for flood-resistant design and construction, and has been adopted by building codes (ASCE 2019). However, ASCE 24 does not adequately address the implications that SLC can have on design flood elevations (ASCE 2014). An updated version of ASCE 24 that accounts for SLC would be a significant benefit toward implementing regulatory design standards across the nation. Just as EO 13690 was developed with input from the engineering community, any future federal regulation should also be crafted in a collaborative setting. In Canada, the engineering profession believes that engineering codes, standards, and work practices should consider climate change, and that state, federal, and provincial governments must collaborate with the engineering profession on climate change policies for the benefit of the public (Engineers Canada 2013). 
Additionally, there is also a need for design guidance, especially in the absence of design standards. Design standards, such as ASCE 24-14, provide minimum design requirements and prescriptive actions engineers must take, but may be conservative to cover a broader range of variable conditions. Design guidance is developed to help decision makers assess and incorporate best available information, but does not require the utilization of that information. In the context of SLC, design guidance could be developed to highlight guiding principles for enhancing resilience, provide a step-bystep approach to incorporating SLC projections, and provide context through case study examples of projects that have incorporated SLC. Due to the geographic variability in SLC and other coastal hazards, guidance may be best established at local levels where more focus can be given to site-specific design variables.

\section{Limitations of Research}

This was the first nationwide survey of port and maritime infrastructure engineers regarding the practice of designing port infrastructure that is resilient to SLC. The sample originated with members of COPRI who have port infrastructure design experience, and expanded through snowball sampling. There were at least 31 different private consulting firms and 11 different port authorities represented in this sample, but of course, there are port infrastructure engineers at other consulting firms and port authorities across the country. It is difficult to determine the total number of consulting firms in the U.S. that work on port infrastructure projects, and therefore, difficult to gauge what portion of the entire population responded to the survey. Survey recipients who did not respond may not be interested in SLC design issues. Therefore, responses may be skewed toward engineers who are aware of the challenges brought by SLC and who have more experience designing port infrastructure projects for SLC.

The researchers designed the survey to gauge the general state of the practice across the U.S. Therefore, the results are not indicative of engineering practice within specific regions, and are not indicative of engineering practice outside of the U.S. SLC impacts will vary, resulting in SLC design challenges to become a greater priority in some regions. The survey was not designed to identify the 
location of specific port infrastructure projects that respondents have worked on. A sample of engineers within specified geographic regions would provide interesting findings for future comparison.

This survey was designed for engineers working for private consulting firms, port authorities, and government agencies. As a result, the researchers may have overlooked potential differences in SLC design approaches between these groups. Separate surveys that target each group individually could reveal differences in approach to designing for SLC. While additional details of engineering practices need to be explored in this area, the researchers feel that this study provides informative baseline data where key issues in the resilient design of port infrastructure can be identified and addressed.

Bifurcated Likert scales used for presenting results is also a limitation of the survey and data collected. Although data analysis was conducted with and without bifurcating the data and results were similar in each instance, results had only slight variations when the data was bifurcated. However, due to the similarity in results of the non-bifurcated data and the data that was bifurcated, the researchers believe that bifurcating the data in this way was acceptable.

\section{Conclusion}

SLC design decisions made today have long-term impacts on the resilience of port infrastructure.

Engineers must consider SLC and other coastal hazard impacts when designing port infrastructure to ensure that ports can continue to serve their essential role in the global economy in the coming decades. In serving the public interest, engineers are uniquely qualified and positioned to ensure port infrastructure is resilient for future sea level scenarios. However, adequately designing port infrastructure for SLC is a challenging task due to the uncertainty of SLC projections and the long service lives of port infrastructure. Only $29 \%$ of respondents indicated that their organization had an internal policy or planning document that communicates how to design for SLC. The inconsistencies revealed by this study suggest that the incentive to incorporate SLC into design is inconsistent from project to project, as are the barriers that prevent incorporating SLC into design. Furthermore, SLC projection data varies across NOAA, USACE, IPCC, state and local organizations. 
The engineering community must work with government to develop systematic and practical methods of incorporating SLC into design decisions. Engineers can serve as a bridge between their clients (often port authorities) and regulatory bodies, sharing successful design strategies, influencing the development of design standards and guidance, and helping to transitioning away from the traditional frameworks that operate with assumptions of stationarity. Knowledge sharing between organizations and the adoption of formal guidelines and policies can also promote consistency in the engineering community's approach. In fact, findings from this study suggest that the lack of design standards can lead engineers to disregard SLC entirely. Finally, designing port infrastructure for a theoretical point in time can leave structures at risk if/when they outlive their design life. Although retrofits and upgrades can be implemented in the future, it is far more difficult and expensive to incorporate SLC as an afterthought.

\section{Data Availability Statement}

Some or all data, models, or code generated or used during the study are proprietary or confidential in nature and may only be provided with restrictions (e.g. anonymized data). For example:

- Individual survey responses: As approved by the University of Rhode Island Institutional Review Board, participation and responses to the online survey are confidential and only reported in aggregate.

\section{Acknowledgements}

Thanks to the participants who generously gave their time to assist with this research. A special thanks to the American Society of Civil Engineers and the Coasts, Oceans, Ports and Rivers Institute for their involvement and the financial support they provided for attending conferences and committee meetings. In particular, Scott Hicks, Tom Chase, Mustafa Samad, Tom Ward, and the other members of ASCE's Sea Level Change Subcommittee were influential in the success of this research. This research would not have been possible without them. Thanks also to Dr. Gretchen Macht and Dr. Rob Thompson for feedback and ideas. 


\section{Supplemental Data}

Fig. S1 is available online in the ASCE Library (ascelibrary.org)

\section{$\underline{\text { References }}$}

AAPA (American Association of Port Authorities). 2012. 2012-2016 U.S. port infrastructure investment survey. Alexandria, VA: AAPA.

AAPA (American Association of Port Authorities). 2016. 2016-2020 Port planned infrastructure investment survey. Alexandria, VA: AAPA.

Ahern, J. 2011. "From fail-safe to safe-to-fail: Sustainability and resilience in the new urban world." Landscape and urban Planning, 100(4), 341-343.

Apel, H., G. T. Aronica, H. Kreibich, and A. H. Thieken. 2009. "Flood risk analyses-How detailed do we need to be?" Nat. Hazards 49 (1): 79-98. https://doi.org/10.1007/s11069-008-9277-8.

Asariotis, R., and H. Benamara, eds. 2012. Maritime transport and the climate change challenge. London: Routledge.

ASCE. 2014. Flood resistant design and construction. ASCE/SEI 24-14. Reston, VA: ASCE.

ASCE. 2019. Climate-Resilient infrastructure: Adaptive design and risk management. Committee on Adaptation to a Changing Climate. ASCE Manuals and Reports on Engineering Practice. No. 140. Reston, VA: ASCE.

Atkinson, R., and J. Flint. 2001. “Accessing hidden and hard-to-reach populations: Snowball research strategies." Soc. Res. Update 33 (1): 1-4.

Becker, A., S. Inoue, M. Fischer, and B. Schwegler. 2012. "Climate change impacts on international seaports: Knowledge, perceptions, and planning efforts among port administrators." Clim. Change 110 (1-2): 5-29. https://doi.org/10.1007/s10584-011-0043-7.

Becker, A., J. O. Toilliez, and T. J. Mitchell. 2015. “Considering sea level change when designing marine civil works: Recommendations for best practices." In Handbook of coastal disaster mitigation for 
engineers and planners, edited by M. Esteban, H. Takagi, and T. Shibayama, 697-722. Waltham, WA: Butterworth-Heinemann.

Becker, A. H., et al. 2013. "A note on climate change adaptation for seaports: A challenge for global ports, a challenge for global society." Clim. Change 120 (4): 683-695. https://doi.org/10.1007/s10584-013-0843-z.

Bierling, D., and P. Lorented. 2008. "Ports and climate change: Perceptions and planning practice.” In Proc., 2008 Texas Ports and Waterways Conf. Galveston, TX: Texas Transportation Institute.

Bilbao, R. A. F., J.M.Gregory, andN. Bouttes. 2015. "Analysis of the regional pattern of sea level change due to ocean dynamics and density change for 1993-2099 in observations and CMIP5 AOGCMs.” Clim. Dyn. 45 (9-10): 2647-2666. https://doi.org/10.1007/s00382-015-2499-z.

Biondini, F., and D. M. Frangopol. 2018. "Life-cycle performance of civil structure and infrastructure systems: Survey.” J. Struct. Eng. 144 (1): 06017008. https://doi.org/10.1061/(ASCE)ST.1943541X.0001923.

CACR (Center for Applied Coastal Research). 2019. Coastal List. Newark, DE: University of Delaware. Christodoulou, A., P. Christidis, and H. Demirel. 2018. "Sea-level rise in ports: A wider focus on impacts." Marit. Econ. Logist. 21: 482-496.

Church, J. A., et al. 2013. "Sea level change." In Climate change 2013: The physical science basis. contribution of working group I to the fifth assessment report of the intergovernmental panel on climate change, edited by T. F. Stocker, D. Qin, G.-K. Plattner, M. Tignor, S. K. Allen, J. Boschung, A. Nauels, Y. Xia, V. Bex, and P. M. Midgley, 1137-1216. Cambridge, UK: Cambridge University Press.

COMET. 2019. "Scenario-based planning for sea level change in the U.S. using the USACE sea level change curve calculator and guidance.” MetEd. Accessed date February 8, 2019. https://www.meted.ucar.edu/training_module.php?id=1387\#.Xp27OlhKjlU.

DeConto, R. M., and D. Pollard. 2016. "Contribution of Antarctica to past and future sea-level rise." Nature 531 (7596): 591-597. https://doi.org/10.1038/nature17145. 
Dieng, H. B., A. Cazenave, B. Meyssignac, K. von Schuckmann, and H. Palanisamy. 2017. "Sea and land surface temperatures, ocean heat content, Earth's energy imbalance and net radiative forcing over the recent years.” Int. J. Climatol. 37: 218-229. https://doi.org/10.1002/joc.4996.

Engineers Canada. 2013. Climate change: The profession's position. Ottawa, ON: Engineers Canada.

Esteban, M., H. Takagi, and T. Shibayama. 2013. "Sea level rise and the increase in rubble mound breakwater damage.” In Vol. 2 of Coastal Structures 2011: Proc., 6th Int. Conf., edited by S. Takahashi, M. Isobe, N. Kobayashi, and K. Shimosako, 130-140. Singapore: World Scientific.

Faludi, A., and S. Hamnett. 1977. Flexibility in Dutch local planning. Working Paper No. 28. Oxford, UK: Oxford Polytechnic.

FHWA (Federal Highway Administration). 2012. The federal highway administration's climate change and extreme weather vulnerability assessment framework. Rep. No. FHWA-HEP-13-005. Washington, DC: FHWA.

Hallegatte, S. 2009. "Strategies to adapt to an uncertain climate change." Glob. Environ. Change 19 (2): 240-247. https://doi.org/10.1016/j.gloenvcha.2008.12.003.

Haveman, J. D., and H. J. Shatz. 2006. Protecting the nation's seaports: Balancing security and cost. San Francisco: Public Policy Institute of California.

Headland, J. R., D. Trivedi, and R. H. Boudreau. 2011. "Coastal structures and sea level rise: Adaptive management approach.” In Coastal Engineering Practice 2011, edited by O. T. Magoon, R. M. Noble, D. D. Treadwell, and Y. C. Kim, 449-459. Reston, VA: ASCE.

IPCC (Intergovernmental Panel on Climate Change). 2013. Climate change 2013: The physical science basis: Working group I contribution to the fifth assessment report of the intergovernmental panel on climate change. Rep. No. 1107415322. Cambridge, UK: IPCC.

Jevrejeva, S., L. P. Jackson, R. E. M. Riva, A. Grinsted, and J. C. Moore. 2016. “Coastal sea level rise with warming above $2^{\circ}$ C." Proc. Natl. Acad. Sci. 113 (47): 13342-13347. https://doi.org/10.1073/pnas.1605312113. 
Knox, J. C. 2000. "Sensitivity of modern and Holocene floods to climate change." Quat. Sci. Rev. 19 (15): 439-457. https://doi.org/10.1016/S0277-3791(99)00074-8.

Merz, B., and A. H. Thieken. 2004. "Flood risk analysis: Concepts and challenges.” Österreichische Wasser-und Abfallwirtschaft 56 (3-4): 27-34.

Milly, P. C. D., J. Betancourt, M. Falkenmark, R. M. Hirsch, Z. W. Kundzewicz, D. P. Lettenmaier, and R. J. Stouffer. 2008. "Stationarity is dead: Whither water management?” Science 319 (5863): 573-574. https://doi.org/10.1126/science.1151915.

Neumann, J. E., K. Emanuel, S. Ravela, L. Ludwig, P. Kirshen, K. Bosma, and J. Martinich. 2015. “Joint effects of storm surge and sea-level rise on US coasts: New economic estimates of impacts, adaptation, and benefits of mitigation policy." Clim. Change 129 (1-2): 337-349. https://doi.org/10.1007/s10584-014-1304-z.

NRC (National Research Council). 2012. Sea-level rise for the coasts of California, Oregon, and Washington: Past, present, and future. Washington, DC: NRC, National Academies Press.

Olsen, J. R., ed. 2015. Adapting infrastructure and civil engineering practice to a changing climate. Reston, VA: ASCE.

OPC-SAT (Ocean Protection Council-Science Advisory Team). 2018. State of California Sea-level rise guidance. Sacramento, CA: State of California OPC-SAT.

PANYNJ (Port Authority of New York and New Jersey). 2018. "Request for proposal for the performance of expert professional planning and feasibility study for the wharf replacement program.” New York: PANYNJ.

Parris, A. S., et al. 2012. Global sea level rise scenarios for the United States national climate assessment. Silver Spring, MD: NOAA.

Phillips, E. E. 2019. “At the water's edge, seaports are slowly bracing for rising ocean levels.” The Wall Street Journal, February 11.

Rahmstorf, S. 2007. “A semi-empirical approach to projecting future sealevel rise.” Science 315 (5810): 368-370. https://doi.org/10.1126/science.1135456. 
Rodehorst, B., W. Cooper, D. Ryder, J. Lennon, C. Dorney, R. Kafalenos, and R. Hyman. 2018. Using life cycle cost analyses (LCCAs) to evaluate climate change adaptation measures for transportation projects: A Colorado case study. Rep. No. 18-04966. Washington, DC: Transportation Research Board.

Ruckert, K. L., P. C. Oddo, and K. Keller. 2017. "Impacts of representing sea-level rise uncertainty on future flood risks: An example from San Francisco Bay.” PLoS One 12 (3): e0174666. https://doi.org/10.1371/journal.pone.0174666.

Savonis, M. J., J. R. Potter, and C. B. Snow. 2014. "Continuing challenges in transportation adaptation." Curr. Sustain. Renewable Energy Rep. 1 (1): 27-34. https://doi.org/10.1007/s40518-014-0004-7.

Stedinger, J. R., R. M. Vogel, and E. Foufoula-Georgiou. 1993. "Frequency analysis of extreme events." In Handbook of hydrology, edited by D. R. Maidment, 18.1-18.66. New York: McGraw-Hill.

Stephens, S., R. Bell, and J. Lawrence. 2017. “Applying principles of uncertainty within coastal hazard assessments to better support coastal adaptation.” J. Mar. Sci. Eng. 5 (3): 40. https://doi.org/10.3390/jmse5030040.

Sweeney, B. R. 2019. "Designing port infrastructure for sea level change: A survey of engineers.” M.A. thesis, Univ. of Rhode Island, https://digitalcommons.uri.edu/theses/1464.

Sweet, W. V., R. E. Kopp, C. P. Weaver, J. Obeysekera, R. M. Horton, E. R. Thieler, and C. Zervas. 2017. Global and regional sea level rise scenarios for the United States. OAA Technical Rep. No. NOS CO-OPS 083. Silver Spring, MD: NOAA.

Taneja, P., H. Ligteringen, and W. E. Walker. 2012. "Flexibility in port planning and design.” Eur. J. Trans. Infrastruct. Res. 12 (1): 66-87.

Toilliez, J. O. 2018. "Sea-level change considerations for marine civil works.” ASCE/COPRI Update (PowerPoint Presentation).

UNCTAD (United Nations Conference on Trade and Development). 1985. Port development: A handbook for planners in developing countries. New York: UNCTAD. 
USACE. 2014. Procedures to evaluate sea level change; impacts, responses and adaptation. USACE Approach No. 1443-EN-01. Washington, DC: USACE.

WMO (World Meteorological Organization). 2018. WMO statement on the State of Global Climate in 2017. WMO Rep. No. 1212. Geneva, Switzerland: WMO. 